\title{
Bendita a morte que te acolheu: elementos do judaísmo na construção do personagem Leo, em Aos meus amigos, de Maria Adelaide Amaral
}

Blessed the death which welcomed you: elements of Judaism in the construction of the character Leo, in Aos meus Amigos, by Maria Adelaide Amaral

\author{
Heloiza Montenegro BARBOSA ${ }^{1}$ \\ Ivon Rabêlo RODRIGUES²
}

Resumo: Publicado em 1991, Aos meus amigos foi escrito pela portuguesa Maria Adelaide Amaral, após o suicídio de Décio Bar, amigo da autora desde a época de escola. Maria Adelaide resolveu escrever um livro dedicado ao grupo de amigos mais próximo, uma homenagem e, ao mesmo tempo, um memorial póstumo a Décio. A narrativa - dividida em três partes - acompanha o enterro de Leo: acontecimento que une todos os personagens e os conflitos existentes entre si e consigo mesmos. Leo é o liame que une todos e, mesmo não estando presente fisicamente, apresenta-se como protagonista. As diversas nuances de sua personalidade, características físicas e psicológicas são apresentadas a partir de memórias dos amigos. Entre esses aspectos, o judaísmo apresenta-se como conflito e parte da identidade de Leo, como parte de seu discurso, suas relações e sua morte. $O$ presente artigo procura trazer algumas dessas nuances - focando na relação da religião judaica e o suicídio - e reapresentar Leo dentro desse universo. Para isso, serão usados textos de Schøllhammer (2009) sobre a literatura contemporânea, além de textos religiosos basilares do judaísmo, como o Shulhan Arukh, a Torá e glossários sobre termos judaicos, tais como os de Avery-Peck; Neusner (2004) e Dosick (2007).

Palavras-chave: Judaísmo. Maria Adelaide Amaral. Suicídio.

Abstract: Published in 1991, Aos meus amigos was written by the Portuguese Maria Adelaide Amaral, after Décio Bar, friend of the author since the time of school, having committed suicide. Maria Adelaide decided to write a book dedicated to the closest group of friends, a tribute and, at the same time, a posthumous memorial to Décio. The narrative - which is divided into three parts - accompanies the burial of Leo: an event that unites all the characters and conflicts among themselves and with themselves. Leo is the link that unites everyone and, even though he is not physically present, is the protagonist. The various nuances of his personality, physical and psychological characteristics are presented from his friends' memories. Among these aspects, Judaism presents itself as conflict and part of Leo's identity as part of his discourse, his relationships, and his death. The present article seeks to bring some of these nuances - focusing on the relationship of the Jewish religion and suicide - and to reintroduce Leo into this universe. For this, texts of Schøllhammer (2009) on contemporary literature, and basic religious texts of Judaism, such as the Shulhan Arukh, the Torah, will be used as well as glossaries on Jewish terms by Avery-Peck; Neusner (2004) and Dosick (2007).

Keywords: Judaism. Maria Adelaide Amaral. Suicide.

http://dx.doi.org/10.24024/23579897v28n1a2019p65074

\footnotetext{
${ }^{1}$ Pós-graduada em Literatura Brasileira pela FAFIRE, mestranda em Teoria da Literatura pela UFPE | E-mail: hmontenegro91@gmail.com

${ }^{2}$ Mestre em Teoria da Literatura e orientador da pesquisa | E-mail: ivonrabelo@hotmail.com
} 


\section{Introdução}

Publicado em 1991, o romance Aos Meus Amigos tornou-se uma minissérie, adaptada para televisão pela escritora do livro, Maria Adelaide Amaral. Após o suicídio de Décio Bar - amigo da autora desde a época de escola -, a autora resolveu escrever um livro dedicado ao grupo de amigos mais próximos, uma homenagem e, ao mesmo tempo, um memorial póstumo a Décio.

A história divide-se em três partes sequenciadas, todas acontecendo no mesmo dia. A primeira parte acontece no Cemitério do Araçá, onde Leo é enterrado: acompanha todo o procedimento funerário, desde a liberação do corpo até o enterro. A segunda parte é o momento posterior ao enterro, no qual os amigos se dividem em dois grupos: um vai para a casa de Lúcia, como uma maneira de celebrar a vida e lembrar do amigo que se foi; outro grupo vai para a casa de Leo, à procura de respostas para o suicídio do amigo - ou em busca de um livro que foi/não foi escrito. Na terceira parte ocorre a reunião dos dois grupos que haviam se dividido.

Entre os vários personagens e suas mais diversas conexões (melhores amigos, ex-amantes, ex-cônjuges, inimigos), cada um traz sua história e, com ela, o peso de sua existência. As mais extremas nuances permeiam esses personagens, sendo quase impossível escolher um favorito, aquele com quem o leitor mais se conecta. Todos são amigos entre si e, ao mesmo tempo, todos parecem ser nossos amigos.

O presente artigo procura apresentar Leo sob dois pontos de vista: como personagem de romance e, a partir daí, a sua relação com os aspectos do judaísmo trazidos pela autora para a construção do personagem, além da maneira que o seu suicídio é observado pela religião, fazendo uso de textos basilares do judaísmo, além das cerimônias rituais relacionadas a esse fato. O que é feito, como devia ter ocorrido o cerimonial e como as escrituras - e a realidade - se conectam, onde as tradições milenares do judaísmo podem nos ajudar a entender Leo, como o seu fim é o começo da narrativa e o início do fim das relações com os seus amigos.

\section{Que notícias me dão dos amigos? ? $^{3}$}

Aos meus amigos começa com uma série de ligações telefônicas: entre um telefonema e outro, os amigos compartilham entre si a notícia da morte de Leo. E são ligações - não mais telefônicas - que vão percorrer toda a narrativa: amizades, romances, amantes, amores, amigos. O fio que percorre a vida de uns dos muitos personagens da trama vai conectando-se com a vida dos outros. Essas conexões podem soar largas, distantes, mas existem. Ninguém está só, ninguém viveu sua história solitária. No advento da filmagem do seriado Queridos Amigos, em 2008, a autora - que também foi responsável pela adaptação do romance no seriado de vinte e cinco capítulos - disse em entrevista que havia escrito "(...) para a minha geração, para os meus amigos e queria mostrar o que foi

\footnotetext{
3 “Nada será como antes”, canção de Milton Nascimento e Ronaldo Bastos
} 
e como o período da ditadura marcou suas vítimas"4. Um memorial para essas relações, transformadas em romance.

A todo momento a narrativa é mesclada entre o passado e o presente, misturando os personagens entre as histórias de suas vidas, entrelaçando-os entre um e outro. A vida - e a morte - de Leo é o fio condutor que conecta a todos, e o seu enterro é um momento de apoteose dessas relações e dessas memórias.

A ditadura militar no país havia acabado, deixando para trás uma carga de idealismos e de luta por um país diferente daquele em que viviam. Os amigos, em sua maioria, já estavam na meia idade - os filhos haviam crescido, os casamentos haviam acabado ou encontravam-se no marasmo trazido pelos longos anos juntos - o esvaziamento de ideais e de perspectivas para o futuro. Quando Leo joga-se da janela, "às 6:15h da manhã" (AMARAL, 2008, p. 20), leva consigo muito do que havia sido, e, quando do seu enterro, em que os amigos são "obrigados" a se encontrar novamente, esse esvaziamento de ideais fica ainda mais aparente.

Tal sentimento fica claro nas transcrições das ligações telefônicas entre os amigos, informando sobre o falecimento de Leo, por exemplo. Os amigos se fazem presentes - sendo o enterro mais do que uma despedida, também um reencontro. Colegas da escola, dos vários trabalhos que Leo teve durante a vida, do Partido Comunista, ex-amantes. E nessa junção de pessoas e de histórias, alguns amigos começam a se questionar sobre a existência de um livro que foi - possivelmente - escrito por Leo.

Após o enterro, com todas as dúvidas sobre a existência ou não do romance escrito por Leo, e com um misto de alegria e nostalgia pelo reencontro, o grupo de amigos divide-se: alguns vão com Flora, viúva de Leo, à procura do romance, de alguma mensagem póstuma, ou apenas para ajudar, como apoio emocional ou na limpeza do apartamento; outro grupo desloca-se para a casa de Lúcia, para um jantar, onde todos devem se encontrar no final.

No apartamento de Leo, o grupo espalha-se em busca de rastros do romance ou respostas. Entre fotos, livros e quadros, encontram um toca-fitas com fragmentos de poemas de Sylvia Plath - autora norte-americana que se suicidou aos 33 anos - e trechos de frases de Leo, criando um poema próprio. Posteriormente, enquanto ajuda Raquel na limpeza da casa, Adonis encontra mais um retalho da despedida de Leo, atrás de um quadro, na parede, com trechos de Uma estação no inferno, de Rimbaud (AMARAL, 2008, p. 232). Esses pequenos recados deixados por Leo, espalhados pela casa, acabam tornando-se, para aqueles que o compreendiam - ou ao menos tentavam - pequenos trechos de seu romance, da sua despedida, da sua carta final.

Já a conexão é, de certa maneira, refeita mais à frente, quando, enquanto arruma o quarto do filho, Flora encontra o romance que todos buscavam:

"Flora, dê isto ao Davi quando achar que ele está preparado". Flora abriu a esmo e estremeceu. Era o diário de Leo, o diário da Granja que ele depusera na gaveta de brinquedos do filho,

\footnotetext{
${ }^{4}$ Disponível em: <https://natelinha.uol.com.br/noticias/2008/03/28/maria-adelaide-amaral-fala-sobre-queridos-amigos-no-marilia-gabriela-entrevista-12913.php.>Acesso em: 24 jan. 2019.
} 
certo de que Flora seguramente o encontraria ali. Principiava em 31.12 .72 e na primeira página, numa linha entre aspas, como uma epígrafe, escrevera: "Não é minha culpa, não é culpa de ninguém". E logo abaixo começava: "Sozinho. Como devo chamar isto? Diário da minha angústia? Quase meia-noite. Há uma festa lá fora. Há sempre uma festa lá fora" (...). Suspeitava que fosse o texto que todos procuravam, mas suspeitava também que, mesmo diante da evidência do diário, as pessoas continuassem a procurar o romance, por que era isso que elas queriam encontrar. Ficção. Não. Não havia ficção (AMARAL, 2008, p. 229).

Esse é o momento de redenção entre Leo e Flora: depois de um casamento fadado ao fracasso, um distanciamento pós-divórcio, Flora ainda é a responsável por organizar todo o enterro de Leo, propondo enterrá-lo no jazigo da família, no cemitério do Araçá, e não no cemitério judaico - onde, de acordo com algumas tradições, devem ser enterrados em espaços separados ${ }^{5}$. É nesse momento que Leo conecta-se com o seu passado e seu futuro, com o único herdeiro, seu filho Davi.

A reunião final dos amigos é o momento em que acontecem as trocas de confidências, pequenas transcrições da realidade, declarações de amor e, obviamente, pequenas brigas e grandes dramas, como em toda reunião de família. E o romance encerra-se como começou: com Flora e Lena falando sobre Leo, o único assunto que as conectava de verdade:

\footnotetext{
- Que mais ele dizia no diário? - perguntou Lena (...)

- Ele escreveu sobre literatura, filosofia. Fala da correspondência de Flaubert com Turgueniev, de Hemingway, Walter Benjamin, outros suicidas, da sua incapacidade de escrever a obra definitiva e do seu suicídio inevitável. Lendo o que ele escreveu, é perfeitamente possível prever o que aconteceria. Foi essa a razão e nenhuma outra que ele ocultou os diários de vocês (AMARAL, 2008, p. 333).
}

\section{Alvoroço em meu coração, amanhã ou depois de amanhã}

Maria Adelaide Amaral dedica o livro ao poeta paulista Décio Bar, que havia se suicidado em 1991. Esse fato foi o que levou a autora a escrever o romance, transformando sua amizade com o poeta - e o grupo de amigos que acumulou durante os anos - em narrativa, com o próprio Décio como personagem: Leo. Pouco depois do lançamento do seriado, a família de Décio publicou seus poemas, encontrados postumamente ${ }^{7}$ - assim como Leo, Décio também havia se suicidado. A própria Maria Adelaide Amaral mantinha a carreira de jornalista durante os anos do regime ditatorial no Brasil: um período de ebulição cultural e, ao mesmo tempo, de extrema repressão.

É nesse período que a literatura brasileira começa a desvincular-se da zona rural, do campo, do território inóspito e passa a voltar-se para a cidade, abandonando o bucólico

\footnotetext{
${ }^{5}$ Disponível em: <https://www.cbtbi.org/wp-content/uploads/2016/10/Guide-to-Jewish-Cemetery.pdf> Acesso em: 31 de maio de 2019.

“ "Nada será como antes", canção de Milton Nascimento/Ronaldo Bastos.

7 Disponível em: <https://oglobo.globo.com/cultura/familia-de-decio-bar-que-inspirou-leo-de-queridos-amigos-lanca-livro-postumo-3625304> Acesso em: 10 jan. 2019.
}

LUMEN, Recife, v. 28, n. 1, p. 65-74, jan./jun. 2019 
para o caótico, não só em relação ao espaço onde a narrativa acontece, mas também por fatores estilísticos e temáticos

Geração 90 frequentam os mesmos lugares inóspitos que os escritores da periferia - ruas deterioradas, botecos esquálidos, casas traumatizadas pelo desemprego, pela violência e pela loucura; há uma percepção geral do isolamento e da vulnerabilidade do sujeito moderno (e urbano) (PINTO, 2004, p. 87).

Aos Meus Amigos nos apresenta um grupo de personagens traumatizados, repletos de defeitos, como o próprio Leo, com problemas sérios ligados à bebida, e volátil demais em suas atitudes, entre outros. Nos deparamos, assim, com "a vontade ou o projeto explícito de retratar a realidade atual da sociedade brasileira. Frequentemente pelos pontos de vista marginais ou periféricos" (SCHØLLHAMMER, 2009, p. 53).

Além disso, o romance perpassa diversos aspectos políticos, essenciais para o entendimento do Brasil na época: apesar de nunca ficar explícito o ano em que a narrativa se passa - no seriado, porém, ela se passa em $1989^{8}$-, é possível concluir que a trama se dá no início dos anos $1990^{\circ}$. O início da primeira década de um Brasil recém-democratizado e, ao mesmo tempo, a última década do milênio. Um misto de morte e vida, um respiro no meio do cemitério dos sonhos que muitos deixaram, como afirma Schøllhammer: "Com a abertura política, e durante o processo de retorno à democracia, surge uma escrita mais psicológica que configura uma subjetividade em crise" (SCH ØLLHAMMER, 2009, p. 27).

Outro aspecto importante é a temporalidade da narrativa: pode-se dizer que o texto acaba dividindo-se em dois aspectos temporais, o "atual" e a "memória", acompanhado de um narrador onisciente neutro, fazendo uso da tipologia criada por Norman Friedman, apresentada por Ligia Chiappini Leite (1985, p. 32).

Fazendo uso das informações e análises apresentadas, é possível entender que a obra Aos meus amigos acaba relacionando-se com o que é dito sobre as obras literárias da época, especialmente nas esferas temática, política e histórica pelas quais o país passava. Os amigos são imagens das pessoas que haviam passado pelos tormentos da ditadura e estavam ali, unidos - ou não - para contar suas histórias, na esperança de que nós, leitores, ouvíssemos.

A relação de Leo com o suicídio perpassa questões familiares: ele é o primeiro a encontrar o pai enforcado dentro do banheiro da casa, além do avô que também havia se matado de maneira semelhante. Chegava a acreditar que o suicídio era uma característica genética (AMARAL, 2008, p. 24).

Leo é neto de imigrantes judeus vindo da Bielorrússia, que se fixaram na Rua da Graça, no bairro do Bom Retiro, em São Paulo, onde o pai era peleteiro. Filho único, Leo é assim caracterizado, segundo a autora: "Os Rosemberg eram claros de pele, tinham o cabelo

\footnotetext{
${ }^{8}$ Disponível em: <http://revistaogrito.com/queridos-amigos/> Acesso em: 27 dez. 2018.

${ }^{9}$ Como é que eles puderam confiar naquele mujique safado e falastrão? - exclamou Tito. "Ah meu Deus! Estão falando de Boris leltsin!", Pedro pensou desanimado, desejando que ninguém pedisse sua opinião (AMARAL, 2008, p. 100).
} 
avermelhado e os olhos cinza-esverdeados" (AMARAL, 2008, p. 24). Além disso, Leo era um prodígio, tinha grande talento:

Publicara um livro de poemas aos dezenove anos, excelente, segundo os críticos. Aos 23 tinha feito um curta metragem e ganhara todos os prêmios da categoria. Durante os três anos que cursou arquitetura, dedicou-se às artes plásticas. Chegou a participar de várias coletivas, foi saudado como um artista promissor. Seu texto jornalístico era agudo, claro e simples, sabia quando ser sarcástico, mordaz, engraçado. Tinha estilo, todos reconheciam que era brilhante (AMARAL, 2008, p. 44) ${ }^{10}$.

O primeiro momento em que o judaísmo de Leo é trazido à tona, no livro, acontece em suas primeiras páginas: nas transcrições das ligações telefônicas entre os amigos, avisando sobre o falecimento de Leo. Ivan questiona Lúcia sobre o local do velório, que será realizado no cemitério do Araçá, no Pacaembu, apesar de ele ser judeu (AMARAL, 2008, p. 11) .

A escolha de Flora, que ficara encarregada de todas as decisões do enterro, como não levar o corpo para um cemitério judaico, é pautada pelo suicídio. Mesmo assim, ela procura, limitada pelo seu conhecimento superficial acerca do judaísmo, manter certas tradições: quando o caixão é colocado no espaço reservado para o velório, eles trazem consigo um crucifixo que Flora rejeita, dizendo que Leo "não era cristão" (AMARAL, 2008, p. 29).

O judaísmo é uma religião conhecida - e baseada - por escrituras. Os judeus do passado e os judeus do presente são conectados por tais escrituras e leis, intimamente ligadas à sobrevivência da religião. A junção dessas leis é chamada da Halakhah, do hebreu "caminho", que é o total de leis judaicas, que definem "the Jewish way of life" (AVERY-PECK; NEUSNER, 2004, p. 50). O livro base do Halakhah é a Torá, no qual todos os livros seguintes se inspiraram. E é também na Torá que somos apresentados ao primeiro trecho relacionado ao suicídio: no capítulo 9, versículos 5 e 6 do livro de Bereshit, primeiro livro da Torá - o equivalente ao Gênesis, na Bíblia Cristã:

\footnotetext{
${ }^{5}$ Certamente requererei o vosso sangue, o sangue das vossas vidas; de todo animal o requererei; como também do homem, sim, da mão do irmão de cada um requererei a vida do homem.

${ }^{6}$ Quem derramar sangue de homem, pelo homem terá o seu sangue derramado; porque Deus fez o homem à sua imagem. ${ }^{11}$
}

Em 1565, Joseph Karo publica o Shulhan Arukh, considerado o mais completo código de leis judaicas que contemplam todos os rituais diários, no qual se encontram as leis referentes ao suicídio, usadas como base para definir a maneira como deve-se tratar o suicida, de acordo com a religião:

\footnotetext{
${ }^{10} \mathrm{Na}$ cidade de São Paulo, onde a história se passa, existem dois cemitérios israelitas, segundo o site do Chevra Kadisha Associação Cemitério Israelita de São Paulo, responsável pela administração dos cemitérios israelitas da cidade: o da Vila Mariana, primeiro da cidade, fundado em 1919, e o do Butantã, inaugurado em 1953, que é utilizado até hoje (além dos cemitérios de Embu, na Grande São Paulo, e o de Cubatão, na Baixada Santista).

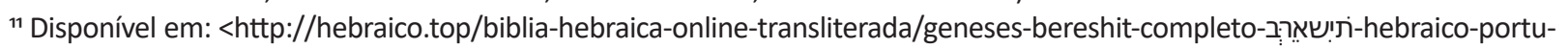
gues-e-transliterado/genesis-bereshit-capitulo-09-תישארב-portugues-hebraico-transliterado/> Acesso em: 8 abr. 2018.
}

LUMEN, Recife, v. 28, n. 1, p. 65-74, jan./jun. 2019 
One who commits suicide wilfully is not attended to at all; and one does not mourn for him and no lamentation is made for him, nor does one rend [garments] or bare [the shoulder in mourning for him], but one stands for him in the line [of comforters], and one recites over him the mourners' blessing, and whatever [brings] honour [only] to the living [may be done]. ${ }^{12}$

O próprio conceito de suicídio apresentado no Shulhan Aruk se estende, de modo a explicar quem pode ser considerado suicida, diferenciando os sujeitos por idade ou circunstâncias do ato. No caso de Leo, segundo as leis, ele seria designado como um suicida comum. Desse modo, a reação de Flora em relação a não enterrá-lo em um cemitério israelita é entendida como uma reação às leis judaicas sobre os suicidas, resumidas por Stephen Weber (1996) no artigo "Ancient Answers to Modern Questions: Death, Dying and Organ Transplants - A Jewish Law Perspective", publicado em 1996: "A suicide victim cannot be buried in a Jewish cemetery. The various rites of mourning which honor the dead, ranging from a eulogy to the rending of garments, are not applicable to a suicide" (WEBER, 1996, p. 29) ${ }^{13}$.

Além de todas essas questões, Leo era ateu. Para entender como esse conceito de Judaísmo transcende a religião: em português não existe diferenciação entre judeu como etnia e judeu como ser religioso, mas em inglês essa dicotomia acontece com o uso das palavras Jewish (etnia) e Judaism (religião). No livro - assim como na língua portuguesa - esses espaços entre ser judeu e seguir o judaísmo são muito estreitos, fundindo-se o tempo todo. Ser ateu não é necessariamente o oposto de ser judeu. A origem dessa dicotomia entre "judeu etnia" e "judeu religião" é explicada por Leonard Mars (2016) após a Revolução Francesa:

\begin{abstract}
Jews became French men and French women of the Jewish religion, similar to Frenchmen who may be Roman Catholic or Protestant. The ethnic element was de-emphasised and was supposed to wither away. In Eastern Europe in the Russian Empire where most of Europe's Jews resided in the Pale of Settlement, the fusion of religion and ethnicity was to persist. Jews were both a people with a religion and a lingua franca in the form of Yiddish (MARS, 2016, p. 39). ${ }^{14}$
\end{abstract}

\footnotetext{
12 "Aquele que comete suicídio intencionalmente não é de modo algum assistido; e um não lamenta por ele e nenhuma lamentação é feita por ele, nem alguém rasga [vestes] ou desnuda [o ombro de luto por ele], mas um representa ele na linha [de edredons], e um recita sobre ele a bênção dos enlutados, e tudo o que [traz] honra [somente] para os vivos [pode ser feito]" (Tradução nossa). Disponível em: <https://www.sefaria.org/Shulchan_Arukh,_Yoreh_De'ah.345.1?lang=bi\&with=all\&lang2=en https://www.myjewishlearning.com/article/suicide-in-jewish-tradition-and-literature/> Acesso em: 08 abr. 2018.

13 "Uma vítima de suicídio não pode ser enterrada em um cemitério judeu. Os vários ritos de luto que honram os mortos, desde um elogio ao rasgar das vestes, não são aplicáveis a um suicídio" (Tradução nossa).

14 "A identidade judaica na Europa antes da Revolução Francesa baseava-se na fusão de dois elementos - um elemento religioso e um elemento étnico. Os judeus eram tanto um povo quanto uma religião. A Revolução Francesa dividiu essa identidade fundida em seus componentes. Na Europa Ocidental, primeiro na França, todos os direitos civis foram concedidos aos judeus franceses para que eles se tornassem cidadãos do Estado francês, membros da nação francesa como indivíduos, mas não como um grupo. A religião tornou-se um assunto privado - uma questão de consciência individual. Os judeus se tornaram homens franceses e mulheres francesas da religião judaica, semelhantes aos franceses que podem ser católicos romanos ou protestantes. O elemento étnico foi menos enfatizado e deveria desaparecer com o tempo. Na Europa Oriental, no Império Russo, onde a maioria dos judeus da Europa residia no Pale of Settlement, a fusão de religião e etnia persistia. Os judeus eram tanto um povo com uma religião quanto uma língua franca na forma de iídiche" (Tradução nossa).
} 
Como é explicado pelo próprio Mars (2016), nos países do Império Russo - como a Bielorrússia, de onde a família de Leo veio - essa cisão não existia. A prova dessa relação aparece principalmente em Flora, que se responsabiliza pelo enterro e, de algum modo, procura seguir os protocolos religiosos, como o caixão fechado e a retirada do crucifixo:

\begin{abstract}
Ateu ou não, era judeu, e ela pedira ao irmão que o deixasse nu e o envolvesse num lençol, para que ele retornasse ao pó, como seus ancestrais. Talvez o mais correto tivesse sido procurar um rabino, mas ela temia que as circunstâncias da morte o privassem de uma cerimônia religiosa e Leo fosse banido para a ala dos suicidas do cemitério judeu (AMARAL, 2008, p. 29).
\end{abstract}

O ritual funerário judaico - Levaiah - "is laconic. The prayers are exceedingly brief." (AVERY-PECK; NEUSNER, 2004, p. 77) ${ }^{15}$. Em geral, a cerimônia deve ser feita o mais rápido possível após a morte (DOSICK, 2010, p. 303) ${ }^{16}$. Sabendo ou não desse aspecto, a rapidez no processo é também um desejo da própria Flora, que "confiava na promessa de seu irmão de que Leo seria enterrado naquela tarde" (AMARAL, 2004, p. 20).

Além disso - à sua própria maneira, sem conhecer profundamente - Flora também segue o ritual em relação ao tachrichin: "No matter the status of the deceased or the privileged life he or she may have lead, all bodies are wrapped in the same white shroud (tachrichim) prior to being placed in a coffin"17.

Mais à frente, Beny questiona se o amigo havia sido enterrado com o talis, "o xale do bar mitzvah", alegando que "Todo judeu guarda o talis para ser enterrado com ele, religioso ou não" (AMARAL, 2008, p. 132). É também Beny que, no enterro, "improvisa um kadish" (AMARAL, 2008, p. 151), uma oração funerária.

O talis é um xale de orações, que contém franjas "knotted in a certain way to symbolically represent the number 613-the number of commandments in the Torah" (DOSICK, 2010 , p. 221 ${ }^{18}$. Essas franjas - chamadas de tzitzit - servem como lembrança constante dos mandamentos, da obrigação de segui-los. O uso constante do talis está muito mais ligado ao modo como a pessoa se conecta com o judaísmo, além de qual modelo usar arban kanfot ou o tallit katan.

Também é Beny que recita um kadish. Na falta de um rabino, ele cria o seu próprio:

\footnotetext{
15 "é lacônico. As orações são extremamente breves" (Tradução nossa).

16 "O funeral e o enterro são realizados logo após a morte para enfatizar a crença judaica de que a alma - onde está a centelha da vida - retorna imediatamente a Deus que a deu; assim, o corpo - que é a morada terrestre da alma - deve ser devolvido, com a mesma rapidez, ao pó de onde veio. Uma vez que o corpo é apenas o recipiente da alma - e não a própria vida - ele não deve se tornar o objeto da triste veneração, mas deve ser rapidamente devolvido à sua fonte, a poeira da Terra de Deus" (Tradução nossa).

17 "Não importa o status do falecido ou a vida privilegiada que ele ou ela possa ter levado, todos os corpos estão envoltos na mesma mortalha branca (tachrichim) antes de serem colocados em um caixão". Disponível em: <http://tepv.org/wpcontent/uploads/2015/07/TEPV_Conservative_Guide_for_Jewish_Burial_and_Mourning.pdf> Acessado em: 15 de jan. 2019. (Tradução nossa).

18 "amarrado de certa forma para simbolicamente representar o número 613 - o número de mandamentos na Torá" (Tradução nossa).
} 
Bendito seja você, Leo, que habitou as sombras (...) Bendito seja você na arrogância, paranoia, no delírio, na pretensão de escrever a obra definitiva (...) Bendita a sua luz que brilhou para mim e mais uns poucos! Bendito o teu fracasso, o álcool que corroeu tuas vísceras, a nicotina que envenenou teu sangue, bendita a coragem de cagar pra vida, bendita a morte que te acolheu! (...) Bendito todos os que como você escolheram as trevas, bendito os loucos, os homossexuais, os bêbados e párias de todas as ordens, bendita a solidão, bendito o desespero que fez você cometer finalmente a grande obra da sua vida! (AMARAL, 2004, p. 152).

O kadish é parte essencial do luto: deve ser recitado diariamente, durante onze meses após o falecimento do ente querido, como uma maneira de "facilitar" a jornada do ser que se foi: "each time a mourner recites kaddish for the deceased, the soul 'earns points' in its heavenly quest" (DOSICK, 2010, p. 308) ${ }^{19}$. Desse modo, é fácil entender a necessidade do kadish para Beny: é uma maneira de ajudar a alma atormentada de Leo na sua busca pela eternidade.

Não se sabe, por exemplo, como foi feito o enterro do pai e avô, se seguiram ou não as tradições funerárias. Leo vivia em um ambiente plural, além de ter se movimentado pelos mais diversos círculos culturais e políticos; logo, a maneira quase "esquizofrênica" - no sentido de sua constante distância da realidade, seu derradeiro isolamento - com que seu enterro acontece é, de certo modo, um retrato de quem ele era, dos amigos que tinha e da vida atribulada que levou.

\section{Considerações finais}

O suicídio é o ato final de transgressão com a religião e a cultura que Leo rejeita - sem efetivamente se desvincular, tanto que sua origem é conhecida e considerada por todos os amigos -, porém é um ato de suprema conexão com o passado, com aqueles que vieram antes: no caso de Leo, o suicídio é um mal de família, mas também é uma herança.

Pensando o judaísmo como a religião baseada nos ensinamentos, resistindo a partir da transferência de seus dogmas, o final de Leo é o seu ponto de intersecção com seu pai, seu avô e sua cultura. E do pó ele veio. E para o pó ele retornou.

Com o personagem Leo, a história não é diferente. A trajetória de seus antepassados é também a sua trajetória, complexa e completa em sua própria maneira. A caminhada desse judeu errante é mais do que geográfica, maior que a espera pela volta do profeta cristão: é uma busca pelas respostas que seus antepassados - seu pai, seu avô - fizeram e que recai sob ele. No final, a resposta está em um romance passado para a geração seguinte, do qual não sabemos a conclusão.

No romance de Maria Adelaide Amaral acompanhamos sua vida através das lembranças e pelas palavras dos amigos: somos apresentados - e conhecemos - um homem amargurado, mas extremamente talentoso, um nômade e um eremita, sempre movido por grandes paixões e uma imensa carga de insatisfação. Complexo, nos vários sentidos da palavra.

O fim da vida de Leo é apenas o início do seu romance - a conclusão do livro de sua vida, guardado entre cadernos antigos, herança para seu filho - que, só com a sua morte, 
será lido pela primeira vez. A previsão de Ivan - o romance dedicado Aos Meus Amigos é concretizada, mesmo que só Flora e Lena saibam disso. O seu kadish não precisará ser repetido por onze meses. A sua busca já acabou. Sua alma foi salva e marcada no papel, como seus antepassados, antes dele mesmo.

\section{Referências}

AMARAL, M. A. Aos meus amigos. São Paulo: Globo, 2008.

ANDERSON, G. K. The legend of the wandering Jew. Providence: Brown University Press, 1965.

AVERY-PECK, A.; NEUSNER, J. The routledge dictionary of judaism (routledge dictionaries). Abingdon-on-Thames: Routlegde, 2004.

DOSICK, R. W. Living judaism: the complete guide to jewish belief, tradition and practice. Nova York: Harper Collins, 2007.

LEITE, L. C. M. O foco narrativo (ou a polêmica em torno da ilusão). São Paulo: Ática, 1985. MARS, L. Reflections on an Atheist Jew. 2016. Disponível em: <http://www.hrpub.org/ download/20160130/SA6-19605387.pdf.> Acesso em: 24 jan. 2019.

NEUSNER, J. Judaism: the basics. Abington-on-Thames: Routledge, 2006.

PINTO, M. da C. Literatura brasileira hoje. São Paulo: Publifolha, 2004.

SCHOLLHAMMER, K. E. Ficção brasileira contemporânea. Rio de Janeiro: Contemporânea, 2009.

74 WERBER, S J. Ancient answers to modern questions: death, dying, and organ transplants- a jewish law perspective. 11 J.L.; Health 13 (1996-1997). Disponível em: <https://engagedscholarship.csuohio.edu/jlh/vol11/iss1/5/> Acesso em: 08 abr. 2018.

Recebido em: 23.05.2019

Aprovado em: 30.05.2019

Para referenciar este texto:

BARBOSA, Heloiza Montenegro; RODRIGUES, Ivon Rabêlo. Bendita a morte que te acolheu: elementos do judaísmo na construção do personagem Leo, em Aos meus amigos, de Maria Adelaide Amaral. Lumen, Recife, v. 28, n. 1, p. 65-74, jan./jun. 2019. 